\title{
Increased expression of survivin in gastric cancer patients and in first degree relatives
}

\section{J Yu', WK Leung', MPA Ebert' ${ }^{3}$ EKW Ng², MYY Go', HB Wang ${ }^{3}$, SCS Chung ${ }^{2}$, P Malfertheiner ${ }^{3}$ and JJY Sung*,I}

'Department of Medicine and Therapeutics, Prince of Wales Hospital, Chinese University of Hong Kong, Shatin, Hong Kong; '2Department of Surgery, Prince of Wales Hospital, Chinese University of Hong Kong, Shatin, Hong Kong; ${ }^{3}$ Department of Gastroenterology, Hepatology, and Infectious Diseases, Otto-von-

Guericke University, Magdeburg, Germany

\begin{abstract}
Survivin was recently described as an apoptosis inhibitor. Its pathogenic role in gastric cancer is largely unknown. Expression of survivin in gastric cancer and non-cancer first-degree relatives, and its association with apoptosis and cyclo-oxygenase-2 expression was investigated. Fifty gastric cancer, 30 non-cancer first-degree relatives, 20 normal controls and five gastric cancer cell lines were studied. Survivin and cyclo-oxygenase-2 were evaluated by reverse transcriptase-polymerase chain reaction, immunohistochemistry and Western blot. Survivin expression was absent from normal gastric mucosa. All five cancer cell lines and 34 out of 50 (68\%) human gastric cancer tissues expressed survivin mRNA. Survivin expression was less frequent (22\%; $P<0.00 \mathrm{I})$ in adjacent non-tumour gastric tissues. Immunohistochemistry and Western blot obtained similar findings. Gastric cancers with survivin expression displayed significantly reduced apoptosis $(P=0.02)$, and associated with cyclo-oxygenase- 2 overexpression at both $\mathrm{mRNA}(P=0.00 \mathrm{I})$ and protein levels $(P=0.04 \mathrm{I})$. Moreover, survivin mRNA was detected in the gastric mucosa of eight (27\%) non-cancer relatives. Expression in non-cancer patients showed positive correlation with $H$. pylori infection $(P=0.004)$. This demonstrates the frequent expression of survivin in gastric cancer and in first-degree relatives. Coexpression of survivin and cyclo-oxygenase-2 may suggest multiple pathways contributing to the inhibition of apoptosis in gastric cancer.

British Journal of Cancer (2002) 87, 9 I -97. doi: I0.1038/sj.bjc.660042I www.bjcancer.com

(c) 2002 Cancer Research UK
\end{abstract}

Keywords: gene expression; survivin; gastric cancer; cyclo-oxygenase-2

Regulation of apoptosis, or programmed cell death, is crucial to the preservation of homeostasis and morphogenesis of human tissue (Vaux et al, 1994). Disturbance of this process by aberrantly extending cell viability or favouring accumulation of transforming mutation is thought to contribute to carcinogenesis (Thompson, 1995). IAP (inhibitior of apoptosis) protein family directly inhibits caspase and pro-caspase molecules that function as potential modulators of the terminal effect phase of cell death and survival (Deveraux et al, 1997; Roy et al, 1997; LaCasse et al, 1998). Survivin, a new member of the IAP family, was recently identified to be a novel antiapoptotic gene (Ambrosini et al, 1997; Adida et al, 1998; Tamm et al, 1998). It inhibits apoptosis by binding specifically to the terminal effected cell death proteases, caspase- 3 and -7 in vitro, thereby inhibiting caspase activity and apoptosis in cells exposed to diverse apoptotic stimuli (Tamm et al, 1998). Survivin expression was reported in several apoptosis related foetal tissues, including lung, liver, heart, and gastrointestinal tract (Adida et al, 1998), but not in differentiated tissues except for placenta and thymus (Ambrosini et al, 1997). Several reports have noticed elevated levels of survivin in tumour tissues when compared to normal tissue

*Correspondence: JJY Sung; Department of Medicine and Therapeutics, Prince of Wales Hospital, Shatin, N.T., Hong Kong;

E-mail: joesung@cuhk.edu.hk

Received 5 April 2002; accepted 25 April 2002
(Ambrosini et al, 1997; Adida et al, 1998; Tamm et al, 1998). The role of survivin in gastric carcinogenesis is, however, largely unknown.

Increased cyclo-oxygenase-2 (COX-2) expression has been demonstrated in the process of gastric carcinogenesis (Ristimaki et al, 1997; Sung et al, 2000; Leung et al, 2001). Considerable evidence suggests that the increase in tumorigenic potential of COX-2 expressing cells is related to the resistance to apoptosis (Tsujii and DuBois, 1995). Although the mechanism underlying COX-2-mediated inhibition of apoptosis is largely unknown, previous studies revealed that COX-2 overexpression in intestinal epithelial cells increased level of IAP (Tsujii and DuBois, 1995). Furthermore, prostaglandin E2, the major product of COX-2, has been shown to increase $b c l-2$ expression, another suppressor of apoptosis, in human colon cancer cells (Sheng et al, 1998). In contrast, treatment with selective COX-2 inhibitors down-regulates $B c l-2$ expression and induces apoptosis (Tsujii and DuBois, 1995). All of these findings indicate that COX-2 is involved in the inhibition of apoptosis signalling by interaction with IAP. In contrast to $b c l-2$, survivin is unique in that it is undetectable in normal adult tissues, but abundantly expressed in transformed cells and a variety of human cancers. Little, however, is known the interaction between COX-2 and survivin.

In the present study, we sought to examine survivin expression in gastric cancer and in first degree-relatives of gastric cancer patients in order to elucidate the role of survivin in the process of gastric carcinogenesis. In addition, we studied the correlation 
between survivin expression and COX-2 activity in cancerous and non-cancerous gastric tissues.

\section{MATERIALS AND METHODS}

\section{Cancer cell line}

The human gastric cancer cell lines KATO III, MKN45, MKN28, AGS and N87 were obtained from Riken Cell Bank (Tsukuba, Japan) and American Type Culture Collection (Rockville, MD, USA). All cell lines, with the exception of Kato III, were maintained in RPMI 1640 medium (Gibco BRL, Gaithersburg, MD, USA) supplemented with $10 \%$ foetal bovine serum (Gibco BRL). Kato III was cultured in 80\% RPMI 1640 medium and 20\% foetal bovine serum.

\section{Gastric tissue samples}

Fifty patients undergoing surgery for primary gastric cancer were examined. There were 33 males and 17 females with a mean age of 62.2 years (range from 36-83). Paired gastric tumours and adjacent normal gastric mucosa were obtained from each patient at the time of surgery. The samples were immediately frozen in liquid nitrogen and were stored at $-80^{\circ} \mathrm{C}$. The remaining tissue specimens were fixed in $10 \%$ formalin and embedded in paraffin for routine histological examination and immunohistochemical analysis. Tumours were reviewed and classified into intestinal or diffuse types according to Lauren, and the disease was staged according to the UICC/AJCC TNM classification (Sobin and Wittekind, 1997). In addition, 30 first-degree relatives of gastric cancer patients and 20 normal control subjects without a family history of gastric cancer were examined. Gastric biopsy specimens were obtained from the gastric antrum and corpus of these patients. Tissues were processed as mentioned above. The severity of gastritis and $H$. pylori colonization of the non-tumorous gastric mucosa was classified according to the updated Sydney system (Dixon et al, 1996). H. pylori infection was documented by histology and rapid urease test. This study was approved by the Ethics Committee of Medical Faculty of the Otto-von-Guericke Univer- sity, Magdeburg and informed consent had been obtained from each subjects.

\section{RT - PCR and sequencing}

Gastric tissue specimens were homogenized with an ultrasound homogenizer. Total RNA was extracted by using RNA Tri Reagents (CINNA/MRC, Cincinnati, Ohio, USA) according to the manufacturer's protocol. One- $\mu \mathrm{g}$ of total RNA was reverse transcribed into cDNA by using dNTPs $(1 \mathrm{mM}), 5 \mathrm{X}$ reverse transcription buffer (500 mM Tris- $\mathrm{HCl} \mathrm{pH} 8.3,250 \mathrm{~mm} \mathrm{KCl}, 50 \mathrm{~mm} \mathrm{MgCl} 2$ and $50 \mathrm{mM}$ DTT), 16 units RNasin, and 2.5 units of AMV reverse transcriptase (Gibco BRL, Life Technologies).

For PCR, the primer sequences and expected product sizes were as follows: survivin, (forward) 5'-GGACCACCGCATCTCTACAT-3' and (reverse) 5'-GCACTTTCTTCGCAGTTTCC-3', 338 base pairs (bp); COX-2, (forward) 5'-AGATCATCTCTGCCTGAGTATCTT 3', (reverse) 5'-TTCAAATGAGATTGTGGGAAAAT-3', $305 \mathrm{bp}$; and $\beta$-actin, (forward) 5'-TGACGGGGTCACCCACACTGTGCCCATCTA-3', (reverse) 5'-CTAGAAGCATTTGCGGTGGACGATGGAGGG-3', $654 \mathrm{bp}$. The reaction was performed at $95^{\circ} \mathrm{C}$ for $1.5 \mathrm{~min}$, and followed by 35 cycles of denaturating at $95^{\circ} \mathrm{C}$ for $24 \mathrm{~s}$, annealing at $58^{\circ} \mathrm{C}$ for $48 \mathrm{~s}$ and extension at $72^{\circ} \mathrm{C}$ for $1 \mathrm{~min}$. The PCR products were separated on $1.5 \%$ agarose gel and saved as digital images (Uvigrab; UVItec, Cambridge, UK) (Figure 1). The sequences of the PCR products were confirmed by automated sequencing (ABI Prism 310 Genetic Analyzer; Perkin Elmer, Branchburg, NJ, USA).

\section{Immunohistochemical staining for survivin and COX-2}

Expression of survivin and COX-2 protein was examined by avidin-biotin complex (ABC) immunoperoxidase method. Deparaffinized sections were treated with $3 \%$ hydrogen peroxide to block endogenous peroxidase activity. After blocking with 5\% normal serum for $20 \mathrm{~min}$, the primary antibody was applied and incubated overnight at $4{ }^{\circ} \mathrm{C}$ for survivin (1:200 dilution; \#500-201, Novus Biologicals, Littleton, CO, USA) and at room

A
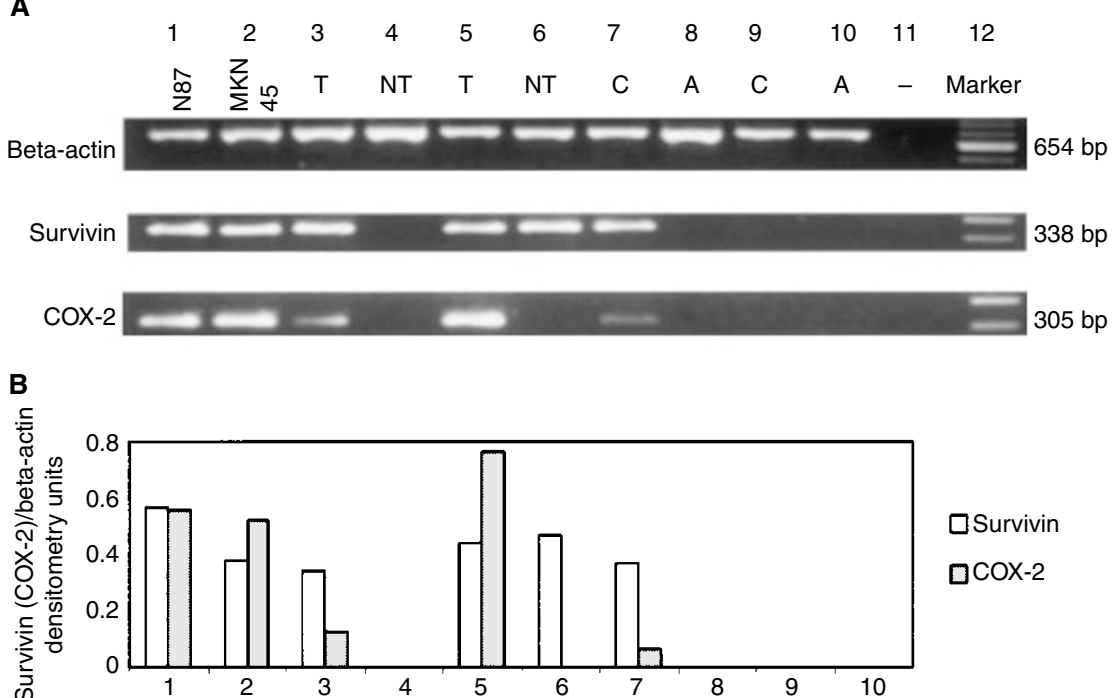

Figure I (A) Expression of survivin and COX-2 mRNA in gastric cancer cell lines (lane I: NCI-N87; lane 2: MKN45), gastric cancer tissues ( $T$ ) and paired non-tumour tissues (NT) (lanes 3-6), corpus (C) and antrum (A) biopsies of first-degree relatives (lanes $7-8$ ) and non-cancer control (lanes $9-10$ ). The 338 bp human survivin-specific sequence, 305 bp human COX-2-specific sequence and a 654 bp $\beta$-actin sequence were amplified from cDNA of gastric cancer cell lines and gastric tissues, separated by agarose gel electrophoresis and visualised by ethidium bromide staining. (B) Densitometry of survivin and COX-2 transcripts, standardised to $\beta$-actin, for the conditions listed above in $\mathbf{A}$. 

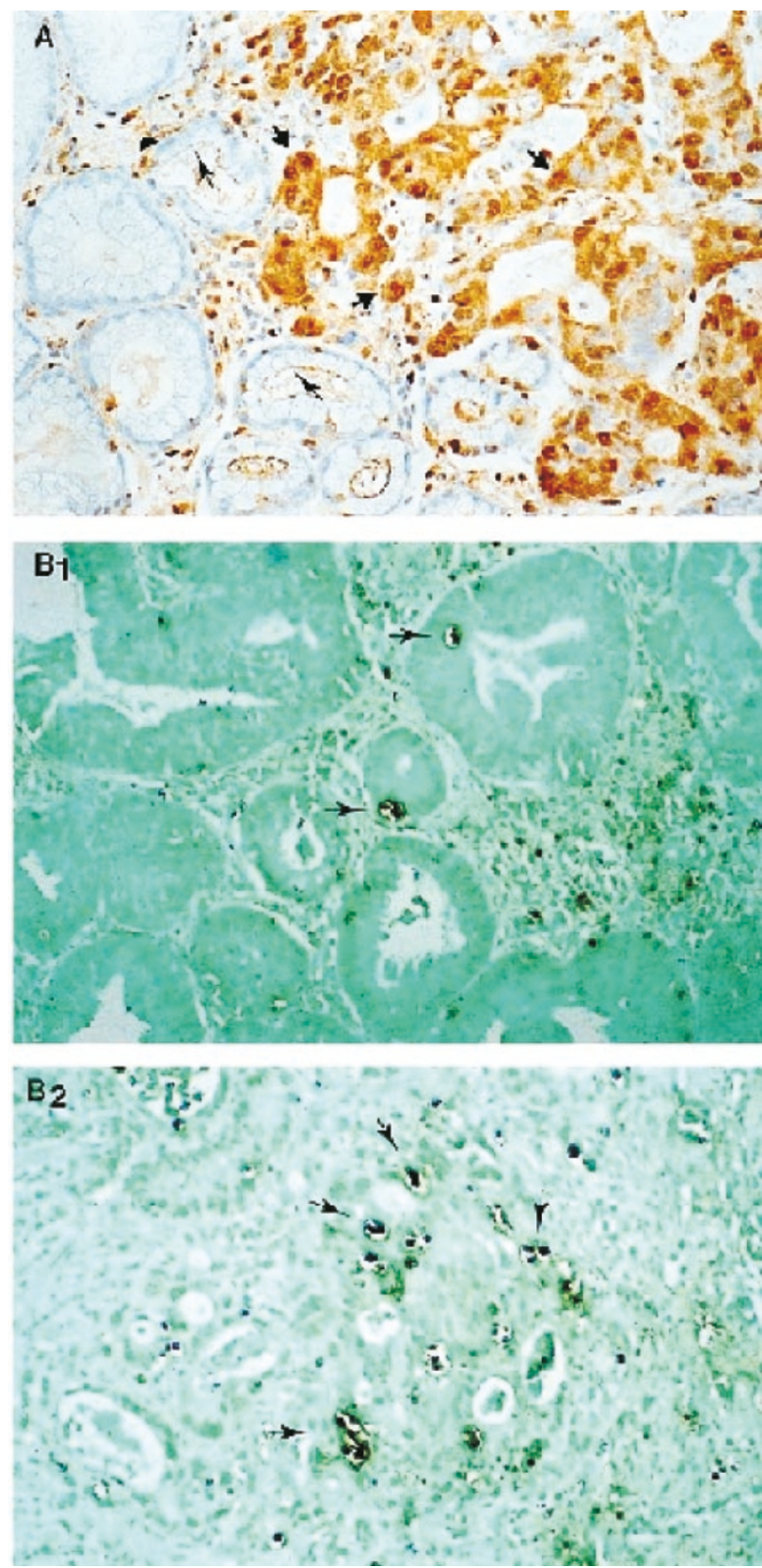

Figure 2 (A) Staining of survivin was mainly restricted to tumour cells (short arrow) but was rarely in the adjacent normal mucosa in this sample (long arrow, $\times 250$ ). (B) Apoptotic nuclei as revealed by TUNEL in survivin-positive tumour (long arrow, $\mathrm{BI}$ ) and in survivin-negative tumour (long arrow, B2, × 250).

temperature for $2 \mathrm{~h}$ for COX-2 (1:100 dilution; \#SC-1745, Santa Cruz Biotechnology, Santa Cruz, CA, USA) respectively. After rinsing, the biotinylated secondary antibody and ABComplex/ HRP (Dako A/S, Denmark) were applied. Peroxidase activity was visualized by applying the diaminobenzidine chromogen. The sections were then counter-stained with haematoxylin. PBS alone without primary antibody was used as negative controls of immunostaining.

Two independent investigators evaluated the immunohistochemical staining without knowledge of the clinico-pathological features of the tumours. For survivin and COX-2, staining in the nucleus and cytoplasm was evaluated by scanning of the whole section and counting more than 1000 representative cells. A semi-quantitative scoring system was used: $0=<5 \%$ of cells with expression;
A

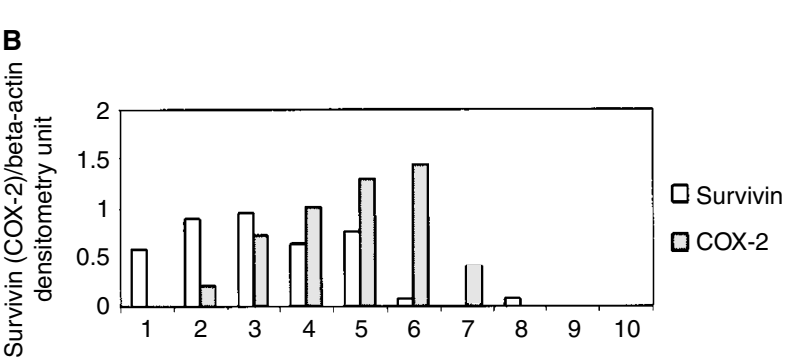

Figure 3 (A) Representative samples of Western blotting for survivin and COX-2 proteins in human gastric cancer cell lines (Katolll, AGS and MKN45), gastric cancer tissues (T), paired non-tumour tissues (NT) and control gastric mucosa $(\mathrm{N})$. The upper panel represents the $\beta$-actin levels as the internal control. (B) Densitometry of survivin and COX-2 proteins, standardised to $\beta$-actin, for the conditions listed above in $(\mathrm{A})$.

$1=5-25 \% ; 2=25-50 \% ; 3=50-75 \%$; and $4=>75 \%$ expression. Cases with weighted scores $<1$ were defined as negative, and were otherwise defined as positive.

\section{Western blot}

Protein was extracted as described previously (Leung et al, 2000a). Gastric tissues and cell lines were homogenized in Tris- $\mathrm{HCl}$ ( $\mathrm{pH}$ 7.4) buffer containing $0.5 \%$ Triton X-100 and protease inhibitor cocktail (Roche, Indiapolis, IN, USA). Protein concentrations were measured by the method of Bradford (Bio-Rad). Sixty micrograms of protein was loaded per lane, separated by $10 \%$ SDSpolyacrylamide gel electrophoresis under reducing conditions, and transferred onto equilibrated polyvinylidene difluoride membrane (Amersham) by electroblotting. Membranes were blocked by $5 \%$ non-fat dry milk and then incubated with an antibody against survivin (dilution $1: 1000$ ) and COX-2 respectively for $3 \mathrm{~h}$. After secondary antibody incubation, survivin and COX2 was detected by enhanced chemiluminescence method (Pierce, Rockford, IL, USA) (Figure 3).

\section{In situ DNA nick end labelling (TUNEL)}

Apoptosis was determined by the terminal deoxynucleotidyl transferase (TdT)-mediated deoxyuridine triphosphate nick-end labelling (TUNEL) technique (ApopTag; Intergen, Purchase, NY, USA) as described previously (Leung et al, 2000b). Nuclei with clear brown staining were regarded as positive (Figure 2B). The apoptosis index was calculated as the percentage of TUNEL-positive nuclei after counting more than 1000 epithelial cells.

\section{Statistical analysis}

Statistical analysis was performed using the Statistical Package for the Social Science program (SPSS, version 9.0). The correlation between survivin expressions and various clinicopathological features of tumours was analysed by using either the $\chi^{2}$ test or Student's $t$-test. The association between survivin and COX-2 was analysed by Spearman's rank correlation analysis. Differences in apoptosis index were analysed by the independent Wilcoxon test. A two-side $P$ value of less than 0.05 was considered statistically significant. 


\section{RESULTS}

Expression of survivin mRNA in gastric cancer and in cancer cell lines

Survivin mRNA expression was undetectable in the normal gastric mucosa by RT - PCR. By contrast, all five cancer cell lines, exhibited survivin expression. Among the 50 gastric cancer samples, survivin mRNA was detected in $34(68 \%)$ cases whereas $11(22 \%)$ of the adjacent non-tumour samples demonstrated survivin expression $(P<0.001)$. Survivin mRNA was, however, not detected in the neigh- bouring normal tissues when the corresponding cancer tissues were negative (Figure 1, Table 1). There was no association between survivin expression and clinical-pathological parameters of the gastric cancers including patients' demographic data, tumour staging, presence of lymph node metastasis and tumour subtypes (Table 2).

\section{Survivin protein expression in gastric cancer and cancer cell lines}

Survivin protein expression was studied by Western blot and immunohistochemistry in 24 randomly selected gastric cancers

Table I Cancer patients characteristics, clinical and molecular findings

\begin{tabular}{|c|c|c|c|c|c|c|c|c|c|c|c|}
\hline \multirow[b]{3}{*}{ Patient } & \multirow[b]{3}{*}{ Age } & \multirow[b]{3}{*}{ Sex } & \multirow{3}{*}{$\begin{array}{l}\text { Histology } \\
\text { Lauren type }\end{array}$} & \multicolumn{4}{|c|}{ Survivin } & \multicolumn{4}{|c|}{ cox-2 } \\
\hline & & & & \multicolumn{2}{|c|}{ mRNA } & \multicolumn{2}{|c|}{ Protein* } & \multicolumn{2}{|c|}{ mRNA } & \multicolumn{2}{|c|}{ Protein } \\
\hline & & & & $\mathbf{T}$ & NT & $\mathbf{T}$ & NT & $\mathbf{T}$ & NT & $\mathbf{T}$ & NT \\
\hline 1 & 36 & $\mathrm{~F}$ & diff & + & - & & & + & - & & \\
\hline 2 & 79 & $M$ & int & + & - & & & + & + & & \\
\hline 3 & 79 & $M$ & int & - & - & & & - & - & & \\
\hline 4 & 63 & $M$ & int & + & - & & & + & - & & \\
\hline 5 & 79 & $\mathrm{~F}$ & int & + & + & & & + & + & & \\
\hline 6 & 61 & $M$ & int & + & - & & & + & - & & \\
\hline 7 & 60 & $M$ & int & - & - & & & - & - & & \\
\hline 8 & 62 & $M$ & diff & + & - & & & + & - & & \\
\hline 9 & 52 & $M$ & int & - & - & 0 & 0 & + & + & 4 & 0 \\
\hline 10 & 72 & $\mathrm{~F}$ & diff & + & - & & & + & + & & \\
\hline 11 & 79 & $\mathrm{~F}$ & int & - & - & & & + & + & & \\
\hline 12 & 69 & $M$ & int & - & - & & & + & + & & \\
\hline 13 & 51 & $M$ & int & + & - & & & + & + & & \\
\hline 14 & 45 & $M$ & diff & - & - & & & - & - & & \\
\hline 15 & 69 & $M$ & diff & - & - & & & + & + & & \\
\hline 16 & 64 & $\mathrm{~F}$ & diff & - & - & & & + & + & & \\
\hline 17 & 76 & $\mathrm{~F}$ & diff & - & - & 0 & 0 & + & + & 4 & 4 \\
\hline 18 & 63 & $M$ & int & + & - & & & + & + & & \\
\hline 19 & 57 & $M$ & int & + & - & & & + & + & & \\
\hline 20 & 50 & $M$ & diff & + & - & & & + & - & & \\
\hline 21 & 43 & $M$ & int & + & - & & & + & + & & \\
\hline 22 & 74 & $\mathrm{~F}$ & diff & + & - & & & + & + & & \\
\hline 23 & 76 & $M$ & diff & - & - & 0 & 0 & - & - & 0 & 0 \\
\hline 24 & 64 & $M$ & mix & + & - & & & - & - & & \\
\hline 25 & 73 & $\mathrm{~F}$ & diff & + & + & 2 & 1 & + & - & 2 & 0 \\
\hline 26 & 50 & $M$ & diff & - & - & 0 & 0 & - & - & 1 & 1 \\
\hline 27 & 64 & $M$ & diff & + & + & & & + & + & & \\
\hline 28 & 72 & $\mathrm{~F}$ & int & + & + & 0 & 0 & - & - & 0 & 1 \\
\hline 29 & 59 & $\mathrm{~F}$ & int & - & - & 1 & 0 & - & - & 1 & 0 \\
\hline 30 & 77 & $M$ & int & + & - & 4 & 0 & + & - & 3 & 0 \\
\hline 31 & 65 & $M$ & int & - & - & 0 & 0 & - & - & 0 & 0 \\
\hline 32 & 43 & $M$ & diff & + & + & 2 & 0 & - & - & 0 & 0 \\
\hline 33 & 62 & $M$ & mix & + & + & 3 & I & + & - & 4 & 2 \\
\hline 34 & 80 & $\mathrm{~F}$ & int & + & - & 4 & 0 & + & + & 1 & 0 \\
\hline 35 & 69 & $M$ & int & - & - & & & + & + & & \\
\hline 36 & 50 & $M$ & diff & + & - & 4 & 3 & + & - & 4 & 2 \\
\hline 37 & 51 & $M$ & $\operatorname{mix}$ & + & - & 3 & 3 & + & + & 2 & 0 \\
\hline 38 & 77 & $M$ & int & + & + & 4 & 0 & + & + & 4 & 2 \\
\hline 39 & 60 & $\mathrm{~F}$ & diff & + & + & & & + & + & & \\
\hline 40 & 70 & $M$ & int & - & - & 0 & 0 & - & - & 0 & 0 \\
\hline 41 & 54 & $M$ & int & + & - & 0 & 0 & + & - & 4 & 0 \\
\hline 42 & 83 & $\mathrm{~F}$ & int & - & - & 2 & 0 & + & - & 4 & 1 \\
\hline 43 & 72 & $M$ & int & + & - & 4 & 1 & + & + & 2 & 1 \\
\hline 44 & 70 & $\mathrm{~F}$ & int & + & - & 4 & 0 & - & - & 2 & 0 \\
\hline 45 & 70 & $\mathrm{~F}$ & int & + & - & & & - & - & & \\
\hline 46 & 52 & $M$ & diff & + & - & 4 & 4 & + & - & 4 & 1 \\
\hline 47 & 74 & $\mathrm{~F}$ & diff & + & + & & & + & + & & \\
\hline 48 & 58 & $M$ & int & + & + & 4 & 0 & + & - & 4 & 0 \\
\hline 49 & 77 & $M$ & int & + & - & 2 & I & + & + & 1 & 0 \\
\hline 50 & 75 & $\mathrm{~F}$ & int & + & + & 4 & 0 & + & - & 4 & 0 \\
\hline
\end{tabular}

T=tumour; NT=adjacent non-tumour; +=positive; -=negative; int=intestinal; diff=diffuse. *Score of protein expression by immunostaining as described in Materials and Methods. 
Table 2 Association between tumour expression of survivin mRNA and clinicopathological characteristic of patients with gastric cancer

\begin{tabular}{llccc}
\hline Variable & Category & Total no & $\begin{array}{c}\text { Survivin } \\
\text { positive no (\%) }\end{array}$ & P value \\
\hline Sex & Male & 33 & $22(66.7)$ & $>0.05$ \\
Age & Female & 17 & $12(70.6)$ & \\
& $>=60$ y & 35 & $23(65.7)$ & $>0.05$ \\
Lymph node metastasis** & $<60 y$ & 15 & $11(73.3)$ & \\
& Present & 33 & $21(63.6)$ & $>0.05$ \\
Lauren classification & Absent & 14 & $9(64.3)$ & \\
& & & & \\
& Intestinal type & 29 & $19(65.5)$ & $>0.05$ \\
& Diffuse type & 18 & $12(67.9)$ & \\
\hline
\end{tabular}

*Data missed in three cases.

and the corresponding adjacent normal gastric tissues as well as in the gastric mucosa of 20 non-cancer individuals. In keeping with the findings by RT-PCR, there was no positive staining in the normal gastric mucosa tissues from non-cancer patients. In contrast, survivin was strongly expressed in gastric cancer tissues (Figure 2). Staining for survivin was observed primarily in the nuclei but was also weakly present in the cytoplasm. Fifteen out of 24 cases $(62.5 \%)$ of gastric cancers were positive while three $(12.5 \%)$ of the adjacent non-cancer mucosa exhibited survivin protein $(P=0.001)$ (Figure $2 \mathrm{~A})$. Expression of survivin in gastric cancer and cancer cell lines was further confirmed by immunoblot which revealed a $16.5 \mathrm{kDa}$ band protein (Figure 3). Strong expression of survivin protein was demonstrated in 14 of the 24 $(58.3 \%)$ gastric cancer tissues and in all five gastric cancer cell lines. Weak expression was detected in the adjacent normal mucosa whereas survivin protein was undetectable in normal controls. The presence of the respective mRNA moiety was more frequent than the respective protein, due to the diverse sensitivity of the methods used for analysis. However, for survivin a consistent correlation between the survivin protein and mRNA levels was observed.

\section{Survivin expression in first-degree relatives}

A total of 30 first-degree relatives were examined for survivin mRNA expression in the gastric corpus and antrum. Increased survivin expression was seen in seven corpus biopsies (23\%) and in five antral biopsies (17\%) (Table 3). When compared to normal gastric tissues from the 20 control subjects, survivin expression was more frequently detected in both the corpus $(P=0.02)$ and the antrum $(P=0.046)$ of first-degree relatives. Among the 60 specimens obtained from the corpus and antrum of first-degree relatives, six were classified as severe gastritis, 18 as moderate gastritis, 21 as mild gastritis and 15 as normal. Survivin expression was more often increased in gastric biopsies with moderate and severe gastritis $(9 / 24,37.5 \%)$ than in samples with mild or no gastritis $(3 / 36,8.3 \% ; P=0.009)$. In keeping with the findings by RT-PCR, staining for survivin was observed in gastric epithelial cells in two out of 10 first degree relatives.

\section{Survivin expression and $H$. pylori infection}

First-degree relatives and control subjects with proper diagnosis of $H$. pylori infection were studied for the relationship between survivin mRNA expression and $H$. pylori infection. In total, 88 gastric tissue samples from relatives and normal control subjects were analysed. Eight of $30(26.7 \%)$ specimens with $H$. pylori infection showed increased survivin expression, whereas three out of 58 (5.2\%) specimens without $H$. pylori infection had survivin expression $(P=0.006)$.

\section{Correlation between survivin expression and apoptosis}

The relationship between survivin expression and apoptosis index of gastric tumours was studied. In gastric tumours with survivin expression, the mean apoptosis index was $1.07 \%(\mathrm{SD}=0.54)$, which was significantly lower than survivin-negative tumours $(1.80 \%$, $\mathrm{SD}=1.62 ; P=0.02$ ) (Figure $2 \mathrm{~B}$ ).

\section{Correlation between survivin and COX-2 expression}

As shown in Table 1, increased COX-2 mRNA expression was detected in 37 of $50(74 \%)$ gastric cancer and $23(46 \%)$ adjacent non-tumour tissues. By immunohistochemistry, COX-2 protein expression was found in 15 of $24(62.5 \%)$ cancers and four $(16.7 \%)$ adjacent normal specimens. The correlation between survivin and COX-2 expression was evaluated in the same tissue specimens of each individual patient by RT - PCR and by immunohistochemistry. There was a significant correlation at per case level between survivin and COX-2 mRNA expression in gastric tumour samples $(r=0.523 ; P=0.001)$. In agreement with mRNA expression, a similar correlation was demonstrated by parallel immunostaining of gastric cancer specimens $(r=0.420, P=0.041)$. However, a similar correlation could not be demonstrated in adjacent non-tumour tissues and in gastric biopsies obtained from first-degree relatives.

\section{DISCUSSION}

Development of gastric cancer, like many other malignancies, is a multi-step process involving the accumulation of mutations and changes in cell cycle regulatory mechanisms. The detection of these alterations in the early stage of cancer development may shed new light into the gastric carcinogenesis process. Our previous studies showed that these changes are not merely found in gastric cancer cells but also in adjacent non-tumour tissues as well as in firstdegree family members of cancer patients (Ebert et al, 2000; Yu et al, 2000a,b). In this study, survivin mRNA expression was detected in the majority of gastric cancers and in all cancer cell lines. In this regard, two recent studies showed that $35-82 \%$ of gastric cancers express survivin protein by using immunohistochemistry (Lu et al, 1998; Okata et al, 2001). In contrast to previous studies, we also examined survivin expression at the RNA and protein levels. In this study, we demonstrated that survivin was not detected in the gastric mucosa from normal control subjects whereas the adjacent non-tumour gastric mucosa of survivin-positive tumours occasionally expressed survivin. This finding is in keeping with those found in colorectal and oesophageal cancer where survivin expression was demonstrated in adjacent normal tissues (Sarela et al, 2000; Kato et al, 2001).

Past epidemiological studies revealed that first-degree relatives have an approximately three-fold increase in risk of developing gastric carcinoma, suggesting the existence of a genetic susceptibility to cancer (Zanghieri et al, 1990; La Vecchia et al, 1992). In this study, we observed an increased survivin mRNA expression in the gastric mucosa of first-degree relatives but not in normal control. Thus, survivin may play an important role in the early stage of development of gastric cancer within family members. One of the plausible explanations for these findings may be related to $H$. pylori infection. H. pylori infection is considered to be an important triggering factor for gastric carcinogenesis (Correa, 1992). Notably, our present study demonstrates that survivin expression correlates with the severity of gastritis and $H$. pylori infection in non-cancer patients. On the other hand, this appears to contradict with the observation that chronic gastritis and $H$. pylori infection is associated with increased epithelial cell apoptosis (Attallah et al, 1996; Moss et al, 1996; Wagner et al, 1997; Leung et al, 2000b). We speculated that the increased survivin expression in these tissues may be secondary to the pro-apoptotic stimuli induced by $H$. pylori. Up-regulation of survivin, an anti-apoptosis protein, then 
Table 3 Parameters of histological findings and mRNA expression in first degree relatives

\begin{tabular}{|c|c|c|c|c|c|c|c|c|c|c|c|c|c|c|}
\hline \multirow[b]{3}{*}{ No } & \multirow[b]{3}{*}{ Age } & \multirow[b]{3}{*}{ Sex } & \multicolumn{6}{|c|}{ Antrum } & \multicolumn{6}{|c|}{ Corpus } \\
\hline & & & \multicolumn{2}{|c|}{$\begin{array}{c}\text { Gastri- } \\
\text { tis }\end{array}$} & \multirow[b]{2}{*}{ IM } & \multirow[b]{2}{*}{ HP } & \multicolumn{2}{|c|}{ mRNA } & \multicolumn{2}{|c|}{$\begin{array}{c}\text { Gastri- } \\
\text { tis }\end{array}$} & \multirow[b]{2}{*}{ IM } & \multirow[b]{2}{*}{ Hp } & \multicolumn{2}{|c|}{ mRNA } \\
\hline & & & $\mathbf{G}$ & A & & & Survivin & coX-2 & G & A & & & Survivin & cox-2 \\
\hline I & 27 & $M$ & 3 & 3 & - & + & + & - & 2 & 2 & - & + & - & + \\
\hline 2 & 57 & $M$ & 3 & 1 & + & - & - & - & 4 & 2 & + & + & - & - \\
\hline 3 & 28 & $\mathrm{~F}$ & 1 & 1 & - & - & - & - & 1 & 1 & - & - & + & - \\
\hline 4 & 37 & $M$ & 3 & 2 & + & + & + & - & 3 & 3 & - & + & + & + \\
\hline 5 & 64 & $M$ & 3 & 3 & - & + & - & - & 3 & 3 & - & + & - & + \\
\hline 6 & 54 & $\mathrm{~F}$ & 4 & 3 & + & + & + & + & 3 & 3 & - & + & + & - \\
\hline 7 & 67 & $\mathrm{~F}$ & 2 & 1 & - & - & - & - & 3 & 3 & + & + & + & - \\
\hline 8 & 33 & $\mathrm{~F}$ & 3 & 3 & - & + & + & + & 2 & 2 & - & + & - & - \\
\hline 9 & 26 & $\mathrm{~F}$ & 3 & 3 & - & + & - & - & 2 & 2 & - & + & - & - \\
\hline 10 & 42 & $\mathrm{~F}$ & 2 & 1 & - & - & - & + & 4 & 3 & - & - & + & - \\
\hline 11 & 74 & $\mathrm{~F}$ & 4 & 3 & + & + & - & + & 3 & 3 & - & + & + & - \\
\hline 12 & 70 & $\mathrm{~F}$ & 2 & 1 & - & - & - & - & 2 & 1 & - & - & - & - \\
\hline 13 & 41 & $\mathrm{~F}$ & 2 & 1 & - & - & - & - & 2 & 1 & - & - & + & - \\
\hline 14 & 43 & $\mathrm{~F}$ & 3 & 3 & - & + & - & - & 3 & 3 & - & + & - & - \\
\hline 15 & 53 & $\mathrm{~F}$ & 4 & 3 & + & + & - & - & 2 & 2 & - & + & - & - \\
\hline 16 & 64 & $F$ & 1 & 1 & - & - & - & - & I & I & - & - & - & - \\
\hline 17 & 37 & $\mathrm{~F}$ & 4 & 3 & - & + & - & - & 3 & 2 & - & + & - & - \\
\hline 18 & 53 & $M$ & 3 & 2 & - & - & - & - & 2 & I & - & - & - & - \\
\hline 19 & 60 & $\mathrm{~F}$ & 3 & 2 & - & + & - & + & 2 & 2 & - & + & - & -1 \\
\hline 20 & 55 & $\mathrm{~F}$ & 2 & 1 & - & - & - & - & 2 & I & - & - & - & - \\
\hline 21 & 37 & $\mathrm{~F}$ & 3 & 2 & - & + & - & + & 3 & 3 & - & + & - & - \\
\hline 22 & 24 & $\mathrm{~F}$ & 2 & 1 & - & - & - & - & 1 & 1 & - & - & - & - \\
\hline 23 & 49 & $M$ & 2 & 1 & - & - & - & - & 2 & 1 & - & - & - & - \\
\hline 24 & 63 & $M$ & 2 & 1 & - & - & - & - & 2 & 1 & - & - & - & - \\
\hline 25 & 52 & $M$ & 1 & 1 & - & - & - & - & 1 & 1 & - & - & - & - \\
\hline 26 & 41 & $\mathrm{~F}$ & 1 & 1 & - & - & - & - & 1 & 1 & - & - & - & - \\
\hline 27 & 24 & $F$ & 2 & 1 & - & nd & + & - & 2 & 2 & - & nd & - & - \\
\hline 28 & 62 & $M$ & 1 & 1 & - & - & - & - & 1 & 1 & - & - & - & - \\
\hline 29 & 50 & $F$ & 1 & 1 & - & - & - & - & 1 & 1 & - & - & - & - \\
\hline 30 & 72 & $F$ & 1 & 1 & + & - & - & - & 1 & 1 & + & - & - & - \\
\hline
\end{tabular}

offers an advantage to a rapidly growing tumour by slowing down the cell loss rate and ultimately leading to neoplastic transformation. This study may offer a further possible biological link between chronic $H$. pylori infection and gastric cancer development.

In this study, gastric cancers with survivin expression had a reduced apoptosis index, which is in keeping with the previous report by Lu et al (1998). Additionally, these investigators demonstrated an association between survivin and $\mathrm{p} 53$ and $b c \mathrm{c}-2$ expression in gastric cancers. While p53 and $b c l-2$ are involved in the modulation of cell progression and viability, the role of other mediators of apoptosis has not been examined yet. Previously, we have demonstrated COX-2 up-regulation in gastric cancer and pre-neoplastic gastric lesions that may play contribute to the carcinogenesis process (Sung et al, 2000; Leung et al, 2001). Overexpression of COX-2 in intestinal epithelial cells results in inhibition of apoptosis (Tsujii and DuBois, 1995), which is similar to the action of survivin. A key question we have addressed here is whether there is any correlation between COX-2 and survivin expression in gastric tumour. Our results show a strong association between survivin and COX2 expression in gastric cancer. The coexpression of survivin and COX-2 demonstrated in this study is intriguing. Survivin blocks apoptosis by targeting the terminal effector caspase-3 and caspase-7 (Adida et al, 1998; Tamm et al,
1998) whereas stimulation of ceramide may be one of the molecular basis for the anti-apoptotic effect of COX-2 (Chan et al, 1998). Whether there is any link between these intermediate pathways may require further studies. Alternatively, common transcriptional factors may be involved in the co-regulation of survivin and COX2 gene in gastric cancer.

In summary, we have demonstrated the up-regulation of survivin in gastric cancer and the adjacent non-tumour area as well as in a proportion of first-degree cancer relatives. Expression of survivin in gastric cancer was associated with reduced apoptosis and COX-2 expression. On the other hand, expression of survivin in non-neoplastic tissues is closely associated with $H$. pylori infection and gastric inflammation. Collectively, these findings indicate that inhibition of apoptosis regulated by survivin is important in the pathogenesis of gastric cancer.

\section{ACKNOWLEDGEMENTS}

This study was supported by grants awarded from the DAAD and Hong Kong RGC Joint Research Scheme (GHK 00/03) to JJY Sung, and the Land Sachsen-Anhalt $(2775 \mathrm{~A} / 0087 \mathrm{H})$ and the DFG (Eb 187/4-1) to MPA Ebert. 


\section{REFERENCES}

Adida C, Crotty PL, McGrath J, Berrebi D, Diebold J, Altieri DC (1998) Developmentally regulated expression of the novel cancer anti-apoptosis gene survivin in human and mouse differentiation. Am J Pathol 152: $43-49$

Ambrosini G, Adida C, Altieri DC (1997) A novel anti-apoptosis gene, survivin, expressed in cancer and lymphoma. Nat Med 3: 917-922

Attallah AM, Abdel-Wahab M, Elshal MF, Zalata KR, Ibrahim NM, Ezzat F (1996) Apoptosis in chronic gastritis: evaluation of the gastric mucosa by DNA flow cytometry and the expression of the high molecular weight cytokeratin. Hepatogastroenterology 43: $1305-1312$

Chan TA, Morin PJ, Vogelstein B, Kinzler KW (1998) Mechanisms underlying nonsteroidal anti inflammatory drug-mediated apoptosis. Proc Natl Acad Sci USA 95: 681 - 686

Correa P (1992) Human gastric carcinogenesis: a multistep and multifactorial process. First American Cancer Society Award Lecture on Cancer Epidemiology and Prevention. Cancer Res 52: 6735-6740

Deveraux QL, Takahashi R, Salvesen GS, Reed JC (1997) X-linked IAP is a direct inhibitor of cell-death proteases. Nature 388: 300-304

Dixon MF, Genta RM, Yardley JH, Correa P (1996) Classification and grading of gastritis. The updated Sydney System. International Workshop on the Histopathology of Gastritis, Houston 1994. Am J Surg Pathol 20: $1161-1181$

Ebert MP, Yu J, Miehlke S, Fei G, Lendeckel U, Ridwelski K, Stolte M, Bayerdorffer E, Malfertheiner P (2000) Expression of transforming growth factor beta- 1 in gastric cancer and in the gastric mucosa of first-degree relatives of patients with gastric cancer. Br J Cancer 82: $1795-1800$

Kato J, Kuwabara Y, Mitani M, Shinoda N, Sato A, Touama T, Mitsui A, Nishiwaki T, Moriyama S, Kudo J, Fujii Y (2001) Expression of survivin in esophageal cancer: correlation with the prognosis and response to chemotherapy. Int J Cancer 95: $92-95$

LaCasse EC, Baird S, Korneluk RG, MacKenzie AE (1998) The inhibitors of apoptosis (IAPs) and their emerging role in cancer. Oncogene 17: $3247-$ 3259

La Vecchia C, Negri E, Franceschi S, Gentile A (1992) Family history and the risk of stomach and colorectal cancer. Cancer 70: 50-55

Leung WK, Kim JJ, Wu L, Sepulveda JL, Sepulveda AR (2000a) Identification of a second mutL DNA mismatch repair complex (hPMS1 and hMLH1) in human epithelial cells. J Biol Chem 275: $15728-15732$

Leung WK, To KF, Chan FK, Lee TL, Chung SC, Sung JJ (2000b) Interaction of Helicobacter pylori eradication and non-steroidal anti-inflammatory drugs on gastric epithelial apoptosis and proliferation: implications on ulcerogenesis. Aliment Pharmacol Ther 14: 879-885

Leung WK, To KF, Ng YP, Lee TL, Lau JY, Chan FK, Ng EK, Chung SC, Sung JJ (2001) Association between cyclooxygenase-2 expression and missense p53 mutation in gastric cancer. Br J Cancer 84: 335-339

Lu CD, Altieri DC, Tanigawa N (1998) Expression of a novel antiapoptosis gene, survivin, correlated with tumor cell apoptosis and p53 accumulation in gastric carcinomas. Cancer Res 58: $1808-1812$

Moss SF, Calam J, Agarwal B, Wang S, Holt PR (1996) Induction of gastric epithelial apoptosis by Helicobacter pylori. Gut 38: $498-501$

Okata E, Murai Y, Matsui K, Isizawa S, Cheng C, Masuda M, Takano Y (2001) Survivin expression in tumor cell nuclei is predictive of a favorable prognosis in gastric cancer patients. Cancer Lett 163: 109-116
Ristimaki A, Honkanen N, Jankala H, Sipponen P, Harkonen M (1997) Expression of cyclooxygenase-2 in human gastric carcinoma. Cancer Res 57: $1276-1280$

Roy N, Deveraux QL, Takahashi R, Salvesen GS, Reed JC (1997) The c-IAP-1 and c-IAP-2 proteins are direct inhibitors of specific caspases. EMBO J 16: $6914-6925$

Sarela AI, Macadam RC, Farmery SM, Markham AF, Guillou PJ (2000) Expression of the antiapoptosis gene, survivin, predicts death from recurrent colorectal carcinoma. Gut 46: 645-650

Sheng H, Shao J, Morrow JD, Beauchamp RD, DuBois RN (1998) Modulation of apoptosis and Bcl-2 expression by prostaglandin E2 in human colon cancer cells. Cancer Res 58: $362-366$

Sobin LH, Wittekind CH (eds) (1997) TNM Classification of Malignant Tumours. 5th edn. pp 59-62, New York: Wiley-Liss, Inc.

Sung JJ, Leung WK, Go MY, To KF., Cheng AS, Ng EK, Chan FK (2000) Cyclooxygenase-2 expression in Helicobacter pylori-associated premalignant and malignant gastric lesions. Am J Pathol 157: 729-735

Tamm I, Wang Y, Sausville E, Scudiero DA, Vigna N, Oltersdorf T, Reed JC (1998) IAP-family protein survivin inhibits caspase activity and apoptosis induced by Fas (CD95), Bax, caspases, and anticancer drugs. Cancer Res 58: $5315-5320$

Thompson CB (1995) Apoptosis in the pathogenesis and treatment of disease. Science 267: 1456-1462

Tsujii M, DuBois RN (1995) Alterations in cellular adhesion and apoptosis in epithelial cells overexpressing prostaglandin endoperoxide synthase 2 . Cell 83: $493-501$

Vaux DL, Haecker G, Strasser A (1994) An evolutionary perspective on apoptosis. Cell 76: $777-779$

Wagner S, Beil W, Westermann J, Logan RP, Bock CT, Trautwein C, Bleck JS, Manns MP (1997) Regulation of gastric epithelial cell growth by Helicobacter pylori: evidence for a major role of apoptosis. Gastroenterology 113: $1836-1847$

Yu J, Ebert MP, Miehlke S, Rost H, Lendeckel U, Leodolter A, Stolte M, Bayerdorffer E, Malfertheiner P (2000a) alpha-catenin expression is decreased in human gastric cancers and in the gastric mucosa of first degree relatives. Gut 46: 639-644

Yu J, Miehlke S, Ebert MP, Hoffmann J, Breidert M, Alpen B, Starzynska T, Stolte PM, Malfertheiner P, Bayerdorffer E (2000b) Frequency of TPRMET rearrangement in patients with gastric carcinoma and in first-degree relatives. Cancer 88: $1801-1806$

Zanghieri G, Di Gregorio C, Sacchetti C, Fante R, Sassatelli R, Cannizzo G, Carriero A, Ponz de Leon M (1990) Familial occurrence of gastric cancer in the 2-year experience of a population-based registry. Cancer 66: 2047 2051 